\title{
Observation of radiation environment in the International Space Station in 2012-March 2013 by Liulin-5 particle telescope
}

\author{
Jordanka Semkova ${ }^{1, *}$, Tsvetan Dachev ${ }^{1}$, Rositza Koleva ${ }^{1}$, Nikolay Bankov ${ }^{1}$, Stefan Maltchev ${ }^{1}$, Victor Benghin ${ }^{2}$, \\ Vyacheslav Shurshakov ${ }^{2}$, and Vladislav Petrov ${ }^{2}$ \\ 1 Space Research and Technology Institute, Bulgarian Academy of Sciences, Acad. G. Bonchev Str. Block 1, 1113 Sofia, \\ Bulgaria \\ *Corresponding author: jsemkova@stil.bas.bg \\ 2 State Scientific Center of Russian Federation, Institute of Biomedical Problems, Russian Academy of Sciences, \\ Khoroshevskoye shosse 76a, 123007 Moscow, Russia
}

Received 10 October 2013 / Accepted 20 September 2014

\begin{abstract}
Since June 2007 the Liulin-5 charged particle telescope, located in the spherical tissue-equivalent phantom of the MATROSHKA-R project onboard the International Space Station (ISS), has been making measurements of the local energetic particle radiation environment. From 27 December 2011 to 09 March 2013 measurements were conducted in and outside the phantom located in the MIM1 module of the ISS. In this paper Liulin-5 dose rates, due to galactic cosmic rays and South Atlantic Anomaly trapped protons, measured during that period are presented. Particularly, dose rates and particle fluxes for the radiation characteristics in the phantom during solar energetic particle (SEP) events occurring in March and May 2012 are discussed. Liulin-5 SEP observations are compared with other ISS data, GOES proton fluxes as well as with solar energetic particle measurements obtained onboard the Mir space station during previous solar cycles.
\end{abstract}

Key words. space radiation dosimetry - International Space Station - solar energetic particle event - galactic cosmic ray

\section{Introduction}

Humans are exposed to the impact of natural ionizing radiation at any given time anywhere in outer space. Ionizing radiation can induce a variety of harmful biological effects. Thus, it is necessary to quantitatively assess the level of exposure as a basis for estimating the radiation hazard during various manned space activities. Currently, the manned space vehicle, the International Space Station (ISS), is equipped with detectors that monitor the radiation environment in it and around it related to the crew's health. The ISS is located in low-Earth orbit (LEO) where the radiation environment is complex, being composed of galactic cosmic rays (GCRs), trapped particle radiation in the form of Earth's radiation belts, solar energetic particles (SEPs), albedo particles from Earth's atmosphere as well as secondary radiation produced in the shielding materials of the spacecraft and in the human body (Wilson et al. 2002).

GCRs are highly energetic charged particles that originate from sources beyond our Solar System. They are thought to be accelerated at highly energetic sources like neutron stars and supernovae within our Galaxy. Energies of GCRs range from several tens up to $10^{12} \mathrm{MeV}_{\text {nucleon }}{ }^{-1}$. The GCR spectrum consists of $98 \%$ protons and heavier ions (baryon component) and $2 \%$ electrons and positrons (lepton component). The baryon component is composed of $87 \%$ protons, $12 \%$ helium ions (alpha particles) and 1\% heavy ions (Simpson 1983). Up to $1 \mathrm{GeV}$ the flux and spectra of GCR particles are strongly influenced by the solar activity and hence show modulations that are anti-correlated with solar activity (Davis et al. 2001; O’Neill 2006; Nymmik 2007).

The biological impact of space radiation to humans depends strongly on the particle's linear energy transfer
(LET) and is dominated by high LET radiation. Especially important is the effect of the high energy heavy ion component of GCRs (typically referred to as high Z and energy (HZE) particles). Consequently, HZE particles possess high LET and are highly penetrating in the human body, which provides them with a large potential for radiobiological damage (Cucinotta et al. 2004). The deep and prolonged minimum of the descent phase of solar cycle 23 produced a high flux level of GCRs, including a flux of iron ions nearly $20 \%$ higher than that observed in the previous solar minima (Mewaldt et al. 2010).

Other components of the incident radiation field at the ISS orbit are the trapped protons and electrons of Earth's radiation belts (Sawyer \& Vette 1976; Vette 1991). The trapped protons of the inner radiation belt have energies up to a couple of hundreds of $\mathrm{MeV}$ and contribute a large fraction of the dose rates outside and inside the ISS. The trapped protons are encountered by LEO spacecraft in the region of the South Atlantic Anomaly (SAA). Although only about $5 \%$ of the mission time of the ISS is spent in the SAA, the astronauts may collect more than $50 \%$ of their total absorbed dose during this short time period (Apathy et al. 2007; Semkova et al. 2013a). The electrons of the inner and outer radiation belts have energies up to several $\mathrm{MeV}$. These electrons are easily stopped before penetrating the spacecraft interior by the self-shielding of the spacecraft and are mainly of concern to an astronaut in a spacesuit during an EVA (Extra-Vehicular Activity) (De Angelis et al. 2004). Relativistic electrons, the so-called "killer electrons", accelerated in the inner magnetosphere under certain conditions also contribute substantially to the doses obtained during EVAs (Dachev et al. 2012).

A sporadic radiation component in the ISS orbit are the SEPs. They consist of protons, electrons, helium ions, and 
HZE ions with energy ranging from a few tens of $\mathrm{keV}$ to $\mathrm{GeV}$ and the intensity can reach $10^{4} \mathrm{~cm}^{-2} \mathrm{~s}^{-1} \mathrm{sr}^{-1}$. It is now widely agreed that SEPs come from two different sources with different acceleration mechanisms working: solar flares themselves release impulsive short-duration events while the coronal mass ejection (CME) shocks produce gradual events (Cliver \& Cane 2002). The most intense long-duration SEP events, also with the highest energies, are produced by CME-driven shocks. Electrons with energies of $\sim 0.5$ to $1 \mathrm{MeV}$ arrive at the Earth, usually traveling along interplanetary field lines, within tens of minutes to tens of hours. Protons with energies of $20-80 \mathrm{MeV}$ arrive within a few to $\sim 10 \mathrm{~h}$, although some high energy protons can arrive in as early as $20 \mathrm{~min}$. SEP events are relatively rare and occur most often during the solar maximum phase of the 11-year solar cycle. SEP events can influence the radiation situation in LEO in two ways. The first one is the well-known direct penetration of SEPs into the magnetosphere. Only particles with energies higher than the geomagnetic cut-off energy can penetrate into the ISS orbit. The time scale of such phenomena is about one-two days (Golightly et al. 1992; Lobakov et al. 1992). The second way is an increase of the trapped particle flux when SEP particles act as an additional source of particles for trapping and subsequent radial diffusion in the inner magnetosphere. During some geomagnetic conditions SEPs can penetrate in the inner belt region and be trapped there (Shurshakov et al. 1996; Dachev et al. 1998). In such cases the SEPs can change dramatically the radiation environment at LEO. After the SEP event on 19 October 1989, followed by a great geomagnetic storm, the Liulin radiometer-dosimeter onboard the Mir space station registered a second proton belt peaking at $L=3$ (Dachev et al. 1992).

Dose characteristics in LEO depend also on many other parameters such as the solar cycle phase, spacecraft orbit parameters, helio- and geophysical parameters.

For the estimation of the organ doses due to the complex particle radiation environment that the ISS is situated in, measurements in models of the human body (tissue-equivalent phantoms) are essential for radiation risk analysis. Recently two experiments with phantoms have been conducted on the Russian segment of the ISS: the MATROSHKA-R international experiment and the ESA Project MATROSHKA with an anthropomorphic phantom (Dettmann et al. 2007; Reitz \& Berger 2007; Shurshakov et al. 2008; Reitz et al. 2009). The experiment MATROSHKA-R includes the Russian spherical tissue-equivalent phantom (Kartsev et al. 2005), equipped with passive radiation detectors and active instruments for studies of the depth dose distribution at various sides of the organs of a human body exposed to cosmic radiation. Liulin-5 (e.g. Semkova et al. 2010) is an active instrument in the Russian spherical tissue-equivalent phantom. The long-term goal of the Liulin-5 experiment is to study the radiation quantities in the phantom during the changing solar cycle. Results for GCR and trapped proton dose rates, particle fluxes and dose equivalent rates in the phantom from the Liulin-5 experiment obtained during the declining phase of the 23rd solar cycle from June 2007 to 2009 can be found in Semkova \& Koleva (2010), Semkova et al. (2010, 2012, 2013a, 2013b) and Dachev et al. (2011). No SEP events were observed during that time.

The aim of this paper is to present new measurements from the Liulin-5 experiment that concern the maximum of the 24th solar cycle and to compare this new time period with that of the previous study. In Section 2 the Liulin-5 experiment and methodology are presented. Results pertaining to the different
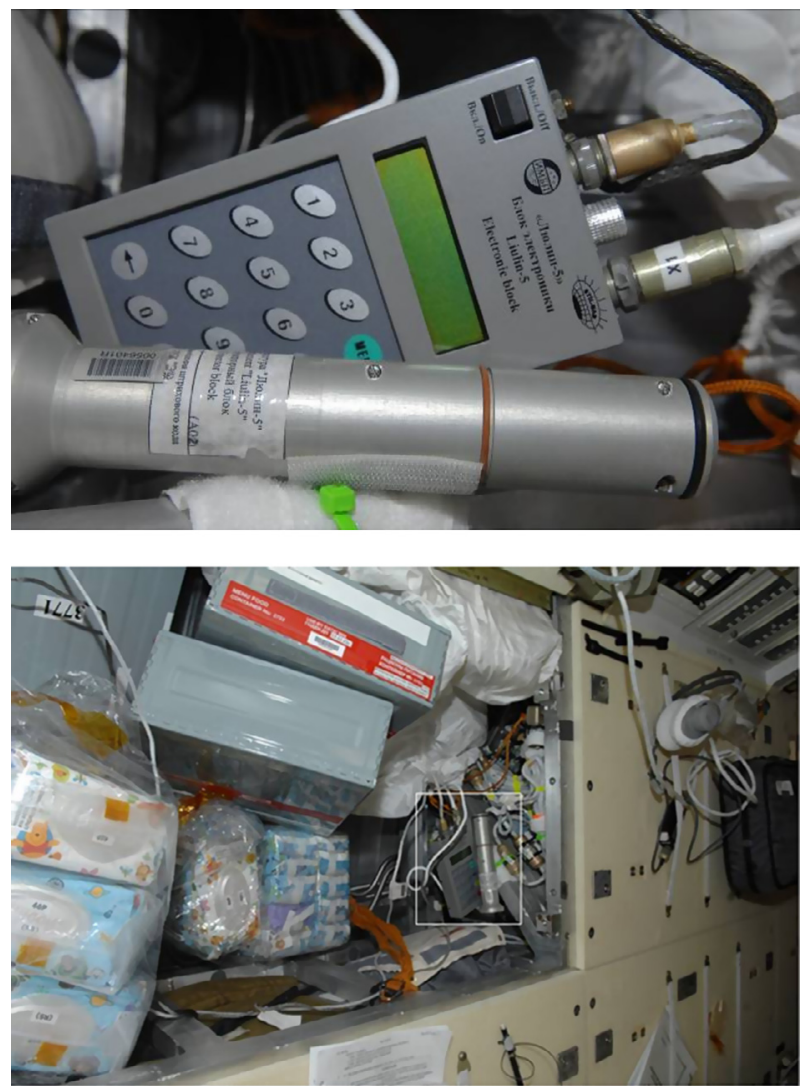

Fig. 1. Upper panel - the Liulin-5 detector module (front) and electronic module (back). Bottom panel - Liulin-5 (marked in the white rectangle) located behind panel 205 in the MIM1 module of ISS.

particle sources (GCR, trapped protons, SEP events) are presented in Section 3. Liulin-5 dose rate results are also compared with dose rate observations made by other detectors during SEP events. The paper ends with a Conclusion.

\section{The Liulin-5 method and instrument}

The ISS Liulin-5 telescope module is comprised of three silicon detectors D1, D2, and D3 (instrument shown in Fig. 1). When measurements are taken inside the phantom, the Liulin-5 particle telescope is mounted inside the largest diameter channel of the phantom (Fig. 2). The detector's axis is along the phantom's radius. The D1 detector is at $40 \mathrm{~mm}$, D2 is at $60 \mathrm{~mm}$, and D3 is at $165 \mathrm{~mm}$ distance from the phantom's surface. The position of D1 and D2 in the phantom corresponds approximately to the shielding of the blood forming organs (BFOs) in the human body, while D3 is placed very close to the phantom's center. This arrangement allows measuring the depth-dose distribution along the sphere's radius. More detailed description of the Liulin-5 method and instrument can be found in Semkova et al. (2010, 2012, 2013a).

Investigation of the ionization radiation environment by the Liulin-5 experiment onboard the ISS has two objectives: (i) measurement of the depth distributions of the energy deposition spectra, flux and dose rates, and absorbed dose D while in the phantom, and measurement of the same parameters in each detector, while outside the phantom; (ii) measurement of the LET spectrum in silicon, and then calculation of the LET spectrum in water and the quality factor $Q$, according 
J. Semkova et al.: Radiation environment in ISS by Liulin-5 data
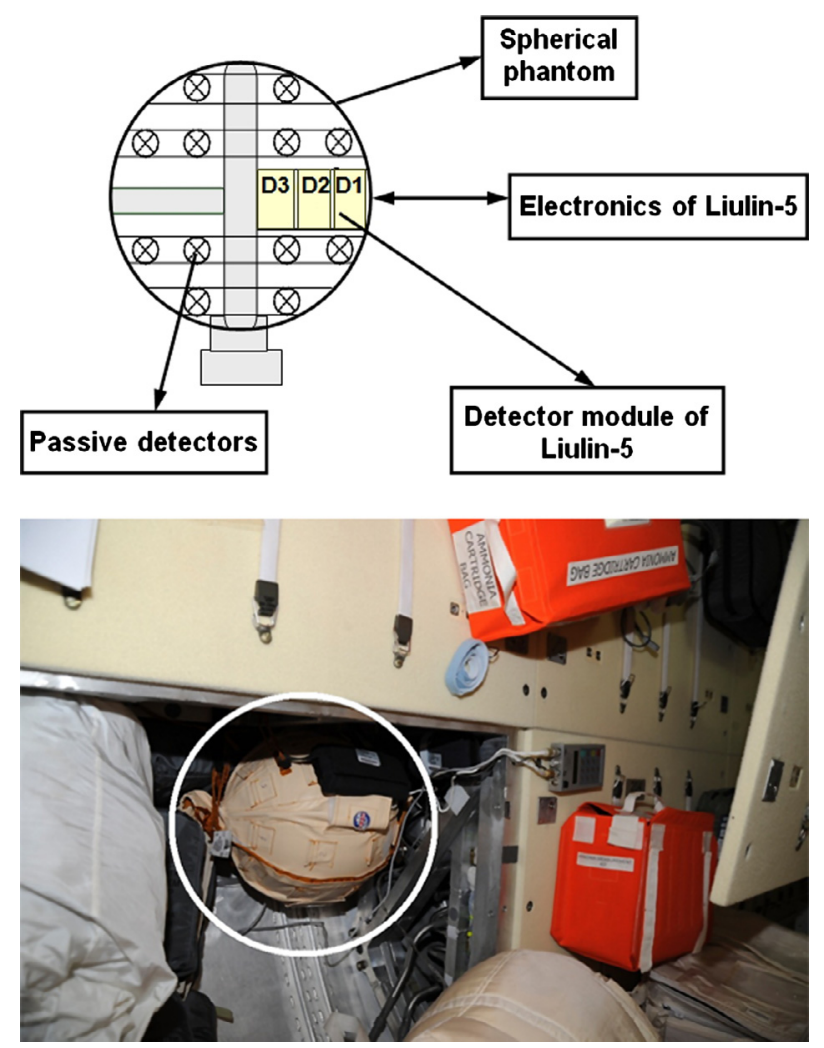

Fig. 2. Liulin-5 in the phantom. Upper panel - sketch of the detectors' arrangement in the phantom. Bottom panel - the spherical phantom (marked in the white circle), located in the MIM1 module behind the panel 206. Inside the phantom (behind the label) is the detector module of Liulin-5.

to the $Q(L)$ relationship given in ICRP 60 (ICRP 1991), where $L$ stands for LET. For radiation protection the quality factor $(Q)$ was introduced to describe the different biological effectiveness of the different radiation types. The biologically significant dose equivalent is obtained as the absorbed dose is weighted by the given quality factor.

The first stage of the Liulin-5 experiment on the ISS took place from June 2007 to June 2010, corresponding to very quiet solar conditions during the deep minimum of the 23rd solar cycle. Liulin-5 was mounted in the PIRS module of the ISS. The second stage of the Liulin-5 experiment has been conducted on the ISS since 27 December 2011 in order to obtain data for the radiation conditions during solar activity increase in the 24th cycle. From 27 December 2011 to 09 March 2013 the Liulin-5 instrument was located in the MIM1 module of the Russian Segment (RS) of the ISS. Measurements both inside and outside the phantom were performed during the second stage of the Liulin-5 experiment.

\section{Result and discussions}

The results presented here originate from the second stage of the Liulin-5 experiment and cover the time interval 27 December 2011 to 09 March 2013. They include flux and dose rates, the obtained average quality factors $\left(Q_{\mathrm{av}}\right)$, and the dose equivalent values during quiet conditions (e.g. no SEP events) and during SEP events.

As mentioned above, during the second stage of the Liulin-5 experiment, the telescope alternated from being
Table 1. Location of the Liulin-5 detector in MIM1 module during the second stage of the experiment on the ISS.

\begin{tabular}{cl}
\hline \hline Time span & \multicolumn{1}{c}{ Liulin-5 location } \\
\hline $27.10 .2011-20.05 .2012$ & $\begin{array}{l}\text { Inside the phantom } \\
\text { (behind panel 206) }\end{array}$ \\
$21.05 .2012-30.08 .2012$ & $\begin{array}{l}\text { Outside the phantom } \\
\text { (behind panel 205) }\end{array}$ \\
$31.08 .2012-11.09 .2012$ & $\begin{array}{l}\text { Outside the phantom } \\
\text { (behind panel 207) } \\
\text { Inside the phantom } \\
\text { (behind panel 206) }\end{array}$ \\
\hline
\end{tabular}

located inside the phantom to outside the phantom. From 27 December 2011 to 20 May 2012 the Liulin-5 detector module was mounted inside the phantom, located behind panel 206 in the MIM1 module of the RS of ISS. Liulin-5 was located outside the phantom behind panel 205 from 21 May 2012 to 30 August 2012 and from 31 August 2012 to 11 September 2012 it was also outside the phantom, but behind panel 207 in MIM1. From 12 September 2012 to 09 March 2013 the Liulin-5 detector module was mounted again inside the phantom located in the MIM1 module behind panel 206. The locations of the Liulin-5 detector in MIM1 are summarized in Table 1.

Panels 205, 206, and 207 are on the right board of the MIM1 module. The sketch of panels on the right board of MIM1 is presented in Figure 3. Figures 1-3 show that there may be differences in the Liulin-5 detector shielding from the surrounding materials while it was behind the different panels in MIM1. Presently we have no data about those differences (if any).

\subsection{Dose rates outside and inside the phantom}

The high time resolution (20 s in SAA and $90 \mathrm{~s}$ outside it) of the particle flux and the dose rate data allows for detailed mapping of their distribution along the ISS orbit. The switching between $90 \mathrm{~s}$ and $20 \mathrm{~s}$ resolution is made automatically, according to a built-in criterion based on the measured particle flux F1 in the D1 detector (Semkova et al. 2010).

The geographical distribution of the dose rate, measured by detector D3 inside and outside the phantom, is shown in the two panels of Figure 4, where $X$-axis is the longitude, $Y$-axis is the latitude, and the dose rate intensity is color coded. Measurements taken inside the phantom for the time intervals from 27 December 2011 to 20 May 2012 and from 12 September 2012 to 09 March 2013 are shown on the upper panel of the figure. The data from measurements outside the phantom in the period 21 May to 11 September are displayed on the bottom panel. In both distributions the maximal dose rates are recorded in the region of the SAA from the trapped protons. Inside the phantom the biggest value recorded is $440.5 \mu \mathrm{Gy} \mathrm{h}^{-1}$, while outside the phantom the maximum dose rate in the SAA is $713 \mu \mathrm{Gy} \mathrm{h}^{-1}$. As can be expected the SAA region has different shape and area for the different types of measurements. Outside the SAA the lowest doses from GCRs $\left(0.36 \mu \mathrm{Gy} \mathrm{h}^{-1}\right.$ inside the phantom and $0.4 \mu \mathrm{Gy} \mathrm{h}{ }^{-1}$ outside it) are obtained near the equator, the highest values of $9-10 \mu \mathrm{Gy} \mathrm{h}^{-1}$ are measured at high geographic latitudes for both inside and outside the phantom.

In Figure 5 the average dose rate distribution measured by detector D3 for the entire interval from 27 December 2011 to 09 March 2013 is plotted (data are averaged for periods of 


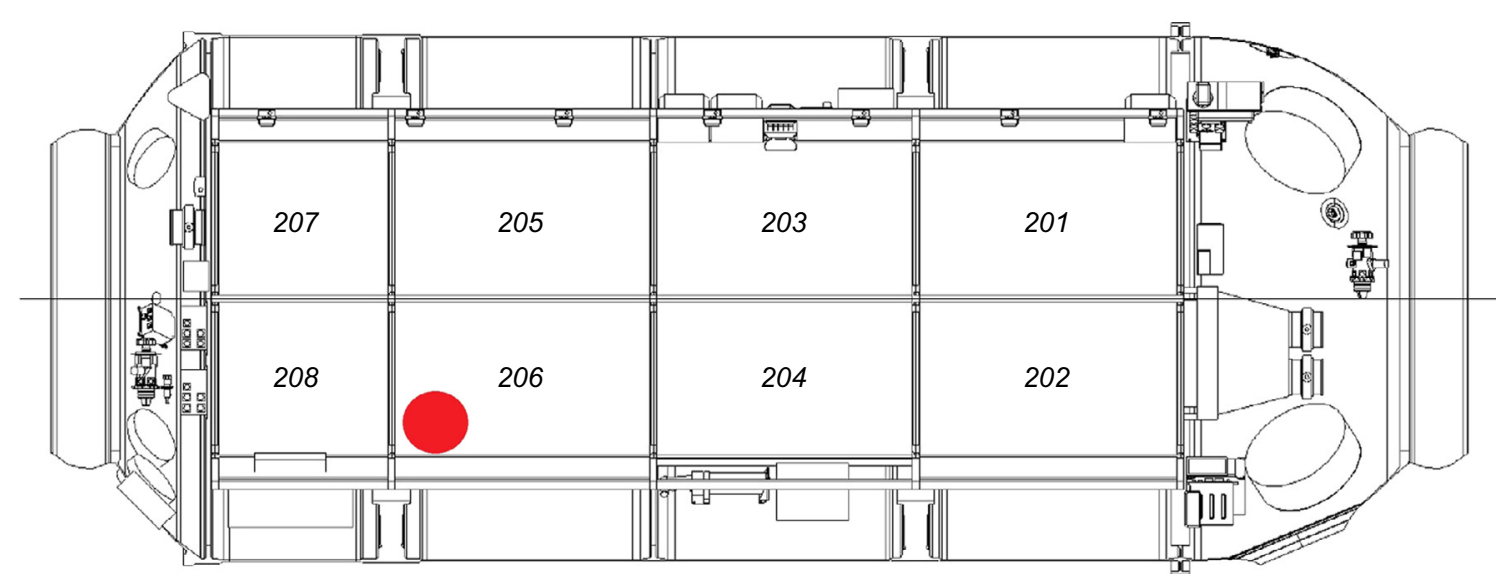

Fig. 3. Sketch of the panels on the right board of MIM1 ISS module. The spherical phantom (red circle) is behind panel 206.

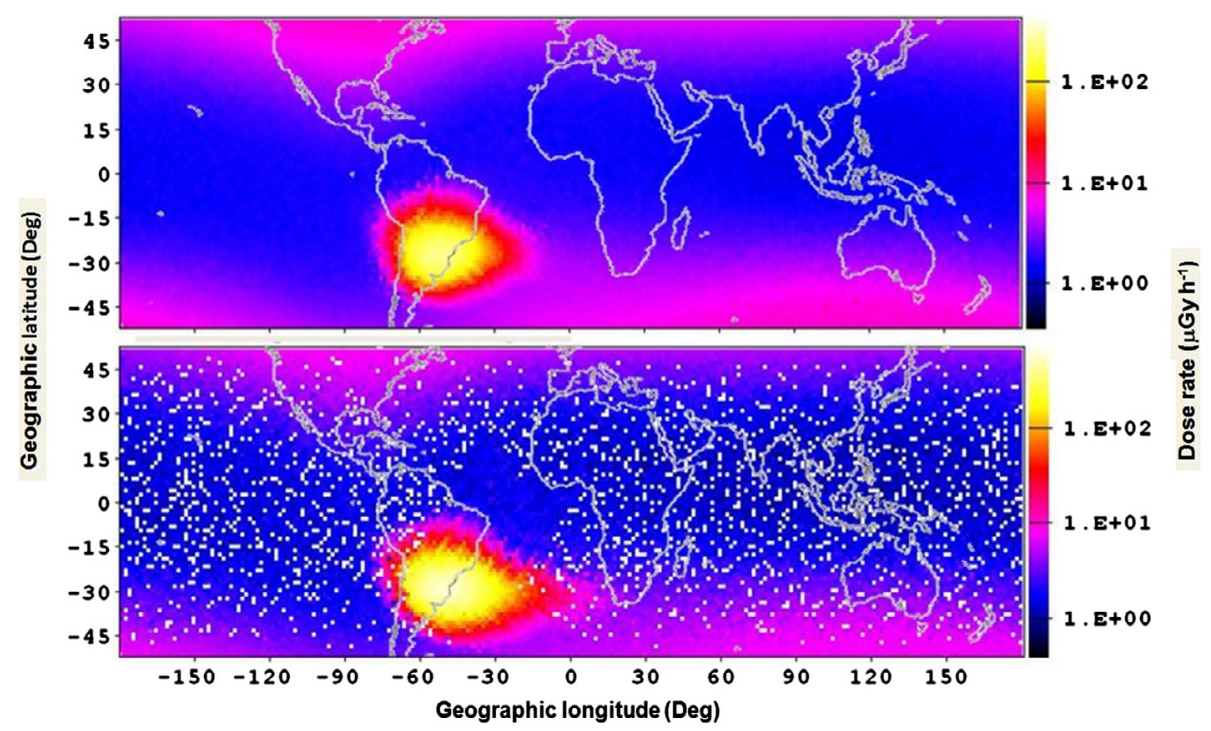

Fig. 4. The geographical distribution of the dose rate recorded by $\mathrm{D} 3\left(\mu \mathrm{Gy} \mathrm{h} \mathrm{h}^{-1}\right)$. Upper panel - measurements inside the phantom for the time intervals 27 December 2011 to 20 May 2012 and 12 September 2012 to 09 March 2013. Bottom panel - measurements outside the phantom in the period 21 May 2012 to 11 September 2012. On the $X$-axis is the longitude, on the $Y$-axis is the latitude, the dose rate intensity is color coded, the small white quadrates indicate the lack of measurements.

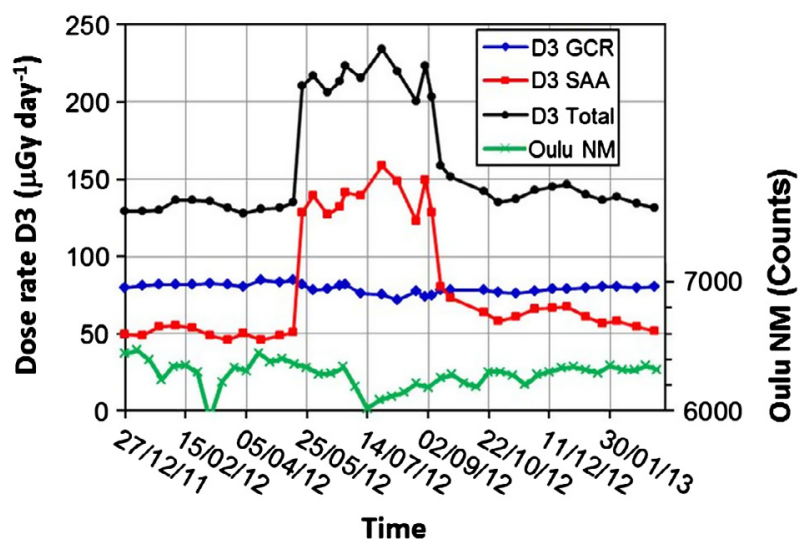

Fig. 5. Averaged dose rate distributions in D3 from 27 December 2011 to 09 March 2013. D3 total is in black, D3 in SAA is in red, and D3 from GCR is in blue. The Oulu neutron monitor count rate data is in green. about 14 days). The total dose rate (black curve) and its individual contributions (GCRs (blue curve), SAA trapped protons (red curve)) are plotted separately. The picture shows that the total dose rates near the phantom's center (130$150 \mu \mathrm{Gy} \mathrm{day}^{-1}$ ) are about 1.7 times less than outside the phantom (200-240 $\mu \mathrm{Gy} \mathrm{day}^{-1}$ for the time interval 21 May-11 September 2012). This decrease is mainly due to the selfshielding of the phantom against the SAA trapped protons. The SAA dose rates are $120-160 \mu \mathrm{Gy}$ day $^{-1}$ outside the phantom and $50-70 \mu \mathrm{Gy}$ day $^{-1}$ near the center of the phantom. The GCR dose rates are $70-85 \mu \mathrm{Gy}_{\mathrm{day}^{-1}}$ (about 1.2 times the maximal difference). The lowest values of the GCR dose rate are in July-August 2012 (when the detector module was located outside the phantom). In Figure 5 the Oulu neutron monitor count rate data (http://cosmicrays.oulu.fi) is plotted for the same period (green curve). It is clearly shown that the behavior of the GCR dose rate is consistent with the Oulu neutron monitor count rate and that the dose rates from GCRs 


\section{J. Semkova et al.: Radiation environment in ISS by Liulin-5 data}

Table 2. Time intervals, averaged dose rates, quality factors, and dose equivalent rates at $40 \mathrm{~mm}$ depth in the phantom obtained outside the SAA during the March 07 and the May 17 SEP events (two upper rows), and during quiet radiation conditions before May 17 SEP event.

\begin{tabular}{cccc}
\hline \hline Time & D1 $\mu \mathrm{Gy} \mathrm{h}^{-1}$ & $Q_{\mathrm{av}}$ & $\mathrm{H} 1 \mu \mathrm{Sv} \mathrm{h}^{-1}$ \\
\hline 07.03.2012, 13:01 UT-08.03.2012, 21:31 UT (SEP event) & 8.43 & 2.5 & 21.1 \\
17.05.2012, 09:50-15:16 UT (SEP event) & 3.24 & 3.75 & 12.15 \\
12.05.2012, 08:36 UT-13.05.2012, 10:32 UT (no SEP event) & 3.2 & 3.9 & 12.48 \\
\hline
\end{tabular}

are practically not affected by the phantom self-shielding. The result confirms our previous investigations that the doses from GCRs at different depths inside the phantom are practically the same and depend mainly on the solar activity (solar max or solar min), but not on the self-shielding of the phantom (Semkova et al. 2012, 2013a).

\subsection{Radiation conditions in the phantom during SEP events in 2012}

\subsubsection{Dose rates and particle fluxes during quiet radiation conditions and during SEP events in 2012}

In 2012 a number of SEP events occurred (23 January, 27 January, 07 March, 13 March, 17 May, 27 May, 16 June, 07 July, 12 July, 17 July, 01 September, 28 September), for which GOES proton $>10 \mathrm{MeV}$ flux exceeded the threshold of 10 part $\mathrm{cm}^{-2} \mathrm{~s}^{-1} \mathrm{sr}^{-1}$ (see http://www.swpc.noaa.gov/ $\mathrm{ftpdir} /$ indices/SPE.txt). However, only the event of March 07 led to significant changes in the radiation environment inside the ISS. Below, the radiation quantities from the Liulin-5 investigations during these SEP events are discussed and the data are also compared to those during undisturbed radiation conditions.

A typical distribution of Liulin-5 particle flux and dose rate data as a function of the $L$-value is presented in the upper scatterplot of Figure 6 taken from Semkova et al. (2013c). The data represent the measurements in detector D1 at $40 \mathrm{~mm}$ depth into the phantom during quiet radiation conditions, about $11 \mathrm{~h}$ after the end of the SEP events observed on the ISS orbit in March 2012 (see Table 2). The two main sources of radiation in LEO (GCRs and the trapped protons of the inner radiation belt in the SAA) are well seen. At $L$-values 1.1-2 both sources contribute to the measured flux. Maximal fluxes of 19.3 part $\mathrm{cm}^{-2} \mathrm{~s}^{-1}$ are registered from the trapped protons in the SAA at $L \sim 1.24$. The maximum dose rate in the SAA was $370 \mu \mathrm{Gy} \mathrm{h}^{-1}$. Minimal values of about 0.035 part $\mathrm{cm}^{-2} \mathrm{~s}^{-1}$ were recorded at $L \sim 1$ from GCR. Outside the SAA the averaged flux from GCR was 0.2 part $\mathrm{cm}^{-2} \mathrm{~s}^{-1}$, the averaged absorbed dose rate $2.65 \mu \mathrm{Gy} \mathrm{h}^{-1}$. At $L>3$ the GCR flux was about 0.7 part $\mathrm{cm}^{-2} \mathrm{~s}^{-1}$, the dose rate was about $9.5 \mu \mathrm{Gy} \mathrm{h}^{-1}$.

On 07 March 2012 GOES-13 registered the beginning of two SEP events (proton fluxes with energy $\geq 10 \mathrm{MeV}$ exceeding the threshold of 10 part $\mathrm{cm}^{-2} \mathrm{~s}^{-1} \mathrm{sr}^{-1}$ ) at geosynchronous orbit. A greater than $100 \mathrm{MeV}$ event began at 04:05 UT on 07 March 2012, reached a maximum of 69 part $\mathrm{cm}^{-2} \mathrm{~s}^{-1} \mathrm{sr}^{-1}$ at 15:25 UT the same day, and ended at 16:50 UT on 10 March 2012. Also, a greater than $10 \mathrm{MeV}$ event began at 05:10 UT on 07 March 2012, reached a maximum of 6530 part $\mathrm{cm}^{-2} \mathrm{~s}^{-1} \mathrm{sr}^{-1}$ at 11:15 UT on 08 March 2012, and ended at 20:50 UT on 12 March 2012. The SEP events were associated with Earth-directed CMEs
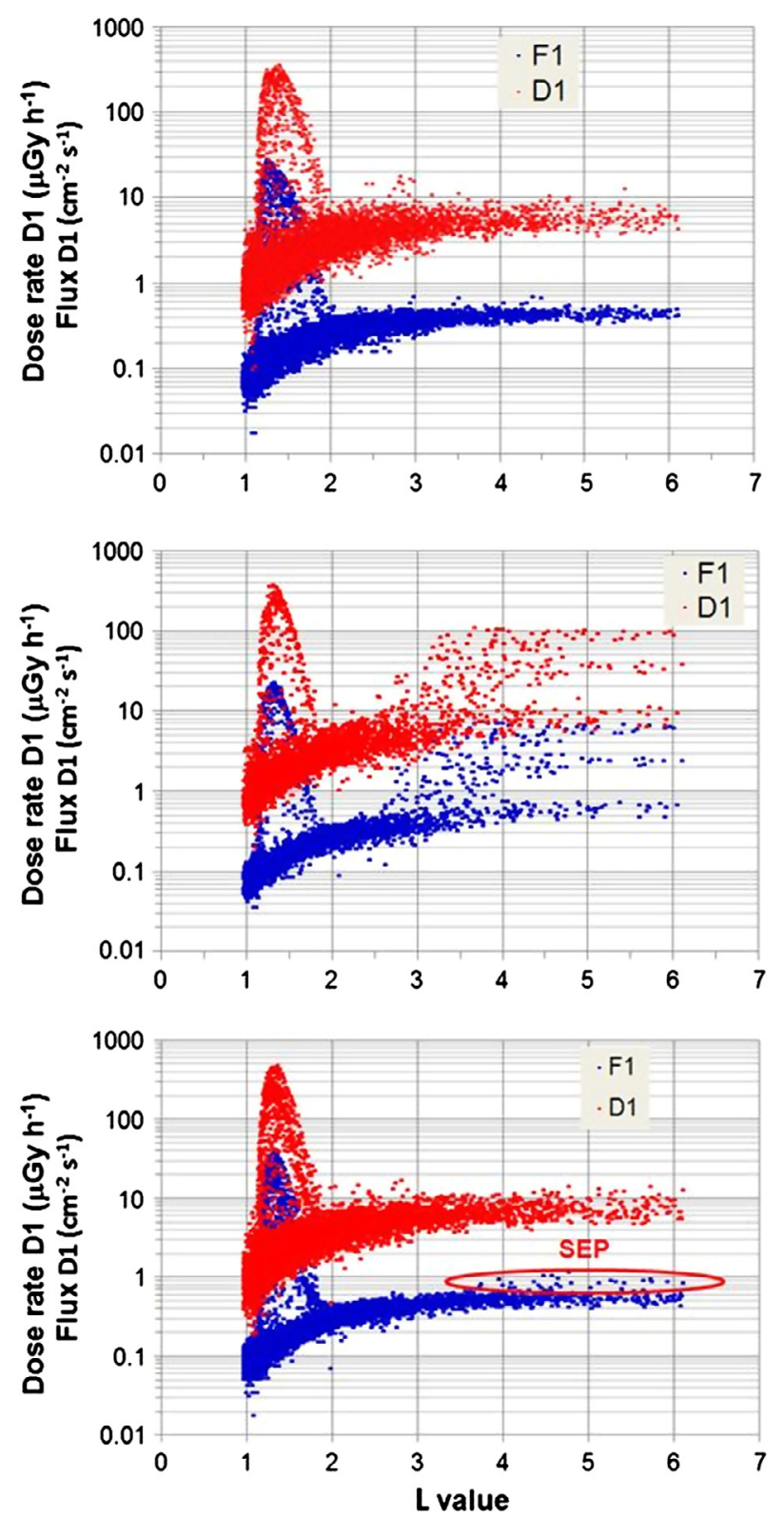

Fig. 6. Distribution of Liulin-5 particle flux F1 (blue) and dose rate D1 (red) as a function of $L$-value. Scatterplots: upper (during quiet conditions), middle (during the SEP events in March 2012), bottom (during the SEP event in May 2012). Upper and middle scatterplots taken from Semkova et al. (2013c).

(ftp://ftp.ngdc.noaa.gov/STP/swpc_products/weekly_reports/ PRFs_of_SGD/2012/03/prf1906.pdf). GOES X-ray flux data are associated with an X5 solar flare (http://www.swpc.noaa. gov/ftpdir/indices/SPE.txt). During these SEP events the Liulin-5 detector module was located inside the phantom. 
The first registration of the particle flux and dose rate increase in Liulin-5 data was on 07 March 2012, at 13:01 UT, at $L=3$, latitude $=-42.3^{\circ}$, longitude $=136.6^{\circ}$, altitude $=415.26 \mathrm{~km}$. This SEP event is discussed in detail in Semkova et al. (2013c). The increase of the particle flux and dose rates at $L>3$ is observed in all three detectors of Liulin-5 located at 40, 60, and $165 \mathrm{~mm}$ depths along the radius of the spherical phantom.

In the middle scatterplot of Figure 6 the distribution of the particle flux and the dose rate in the D1 detector of Liulin-5 (at $40 \mathrm{~mm}$ depth in the phantom) as a function of $L$-value for the time interval 07-09 March 2012 is presented. The comparison with the data during quiet conditions (upper scatterplot) shows that there is no increase of the dose rate and particle flux in the region of the SAA during the SEP events. The maximum flux observed outside the SAA during those SEP events reached 7.2 part $\mathrm{cm}^{-2} \mathrm{~s}^{-1}$ and the dose rate reached $107.8 \mu \mathrm{Gy} \mathrm{h}^{-1}$ on 07 March 2012, 13:06 UT at $L=4$, latitude $=-51.1^{\circ}$, longitude $=166.8^{\circ}$, altitude $=422 \mathrm{~km}$. These values are about 10 times larger than the common GCR dose rates and fluxes at high latitudes.

Another SEP event occurred on 17 May 2012, associated with the M5 solar flare the same day: at 02:10 UT a greater than $10 \mathrm{MeV}$ event began with a maximum of GOES proton flux of 255 part $\mathrm{cm}^{-2} \mathrm{~s}^{-1} \mathrm{sr}^{-1}$ registered on 17 May at 04:30 UT (ftp://ftp.ngdc.noaa.gov/STP/swpc_products/weekly_ reports/PRFs_of_SGD/2012/05/prf1916.pdf); and a greater than $100 \mathrm{MeV}$ proton event began at 02:00 UT and reached a maximum of 20 part $\mathrm{cm}^{-2} \mathrm{~s}^{-1} \mathrm{sr}^{-1}$ at 02:30 UT, ended at 17:25 UT the same day.

In the bottom scatterplot of Figure 6 the distribution of the particle flux and the dose rate in the D1 detector of Liulin-5 as a function of the $L$-value for the time interval 14-20 May 2012 (measurements taken at $40 \mathrm{~mm}$ depth in the phantom) is presented. A slight increase of the dose rate and the particle flux is observed on 17 May since 09:50 UT to 15:16 UT. The maximum flux was 1.15 part $\mathrm{cm}^{-2} \mathrm{~s}^{-1} \mathrm{sr}^{-1}$ and the dose rate reached $14.2 \mu \mathrm{Gy} \mathrm{h}^{-1}$ on 17 May 2012, 09:55 UT at $L=4.8, \quad$ latitude $=-51.3^{\circ}, \quad$ longitude $=151^{\circ}, \quad$ altitude $=$ $413 \mathrm{~km}$.

In Table 2 the averaged dose rates, quality factors, and dose equivalent rates at $40 \mathrm{~mm}$ depth in the phantom obtained outside the SAA during the March 07 and May 17 SEP events, as well as data during quiet radiation conditions before the May 17 SEP event are presented. The table shows that the averaged dose and dose equivalent rates during the March 07 SEP event are higher than the values during non-disturbed conditions. The total additional absorbed dose received from the solar energetic particles was about $180 \mu \mathrm{Gy}$, thus the additional dose equivalent was approximately $448 \mu \mathrm{Sv}$. These values are comparable to the daily absorbed dose and dose equivalent at that depth during quiet periods in 2012 (Semkova et al. 2012).

It is also evident that the averaged dose rate, quality factor, and dose equivalent rate obtained outside SAA during the May 17 SEP event are comparable to those during the quiet period before the SEP event and that the radiation conditions in the phantom were practically not affected by the May 17 SEP event.

\subsubsection{Comparison of Liulin-5 dose rates and GOES proton fluxes during SEP events in 2012}

In the upper plot of Figure 7 the proton flux $F$ with energies $\geq 100 \mathrm{MeV}$ measured by GOES-13 from 07 to 10
March 2012 (http://www.swpc.noaa.gov/ftpdir/warehouse/ 2012/2012_plots/proton/20120309_proton.gif) is shown (blue curve). The dose rate in the D1 detector of Liulin-5 measured outside SAA, and the corresponding $L$-values are plotted versus time for the period from March 07, 07:00 UT to March 10, 00:00 UT, 2012. It is seen that the trend of the Liulin-5 dose rate during that period of the SEP events corresponds to the trend of the proton flux with energies above $100 \mathrm{MeV}$ (the main contribution to the fluxes and doses by Liulin-5 detectors inside the phantom in ISS is from protons of energies above $100 \mathrm{MeV}$ outside ISS). After March 09, 06:00 UT the GOES $\geq 100 \mathrm{MeV}$ proton flux is less than 10 part $\mathrm{cm}^{-2} \mathrm{~s}^{-1} \mathrm{sr}^{-1}$ and the Liulin-5 dose rate goes down to its almost normal values of about $10 \mu \mathrm{Gy} \mathrm{h} \mathrm{h}^{-1}$ at $L>3$.

In the bottom plot of Figure 7 the proton flux $F$ with energies $\geq 100 \mathrm{MeV}$ measured by GOES-13 (http:// www.swpc.noaa.gov/ftpdir/warehouse/2012/2012_plots/proton/ 20120519_proton.gif) is shown (blue curve). The dose rate in the D1 detector of Liulin-5 measured outside the SAA, and the corresponding $L$-values are plotted versus time for the period from May 17, 00:00 UT to May 20, 00:00 UT, 2012. Again the trends of the Liulin-5 dose rate and the proton flux with energies above $100 \mathrm{MeV}$ during that SEP event are similar. The picture shows that when the GOES proton flux with energies greater than $100 \mathrm{MeV}$ reached maximum of about 20 part $\mathrm{cm}^{-2} \mathrm{~s}^{-1} \mathrm{sr}^{-1}$ at 04:30 UT, the ISS was at the low $L$ values part of its orbit. When the ISS orbit entered high $L$ values, the GOES $>100 \mathrm{MeV}$ proton flux was already below 3 part $\mathrm{cm}^{-2} \mathrm{~s}^{-1} \mathrm{sr}^{-1}$. Because of that the dose rate and the particle flux in the ISS did not increase significantly during that SEP event and the SEP event did not affect practically the radiation conditions in the spherical phantom.

During 2012 there were 11 more SEP events listed in http://www.swpc.noaa.gov/ftpdir/indices/SPE.txt for which GOES proton $>10 \mathrm{MeV}$ flux exceeded the threshold of 10 part $\mathrm{cm}^{-2} \mathrm{~s}^{-1} \mathrm{sr}^{-1}$. In three of them - those on 27 May, 16 June, and 01 September there was no change in the GOES proton $>100 \mathrm{MeV}$ flux. During 5 SEPs (on 13 March, 07 July, 12 July, 17 July, and 28 September) the GOES proton flux with energies greater than $100 \mathrm{MeV}$ showed either a slight enhancement or a slight increase. On 23 January 2012 the GOES proton $>100 \mathrm{MeV}$ flux reached only 2 part $\mathrm{cm}^{-2} \mathrm{~s}^{-1} \mathrm{sr}^{-1}$. During the SEP on 27 January the GOES proton $>100 \mathrm{MeV}$ flux increased for about $2 \mathrm{~h}$ around $21 \mathrm{UT}$, but the flux was weak -22 part $\mathrm{cm}^{-2} \mathrm{~s}^{-1} \mathrm{sr}^{-1}$ at maximum and the ISS was at very low $L$-values. (All data for GOES proton fluxes are taken from http://www.swpc.noaa.gov/ftpdir/warehouse/2012/ 2012_plots/proton and from ftp://ftp.ngdc.noaa.gov/STP/ swpc_products/weekly_reports/PRFs_of_SGD/2012/). Thus all these SEP events did not affect significantly the Liulin-5 data either due to the $L$ value location or due to the intensity of the SEPs.

\subsubsection{Comparison of Liulin-5 dose rates during the SEP in March 2012 with measurements during SEPS of previous solar cycles}

The dosimeter-radiometer Liulin onboard the Mir space station (Dachev et al. 1989) was designed for measuring the absorbed dose and flux of penetrating particles using a silicon detector $300 \mu \mathrm{m}$ thick and $2 \mathrm{~cm}^{2}$ area. The device was located in the work section of the space station where the estimated mean mass shielding was about $6-15 \mathrm{~g} \mathrm{~cm}^{-2}$, therefore the main contribution to the device readings was made by electrons and protons with energies outside of the station respectively 

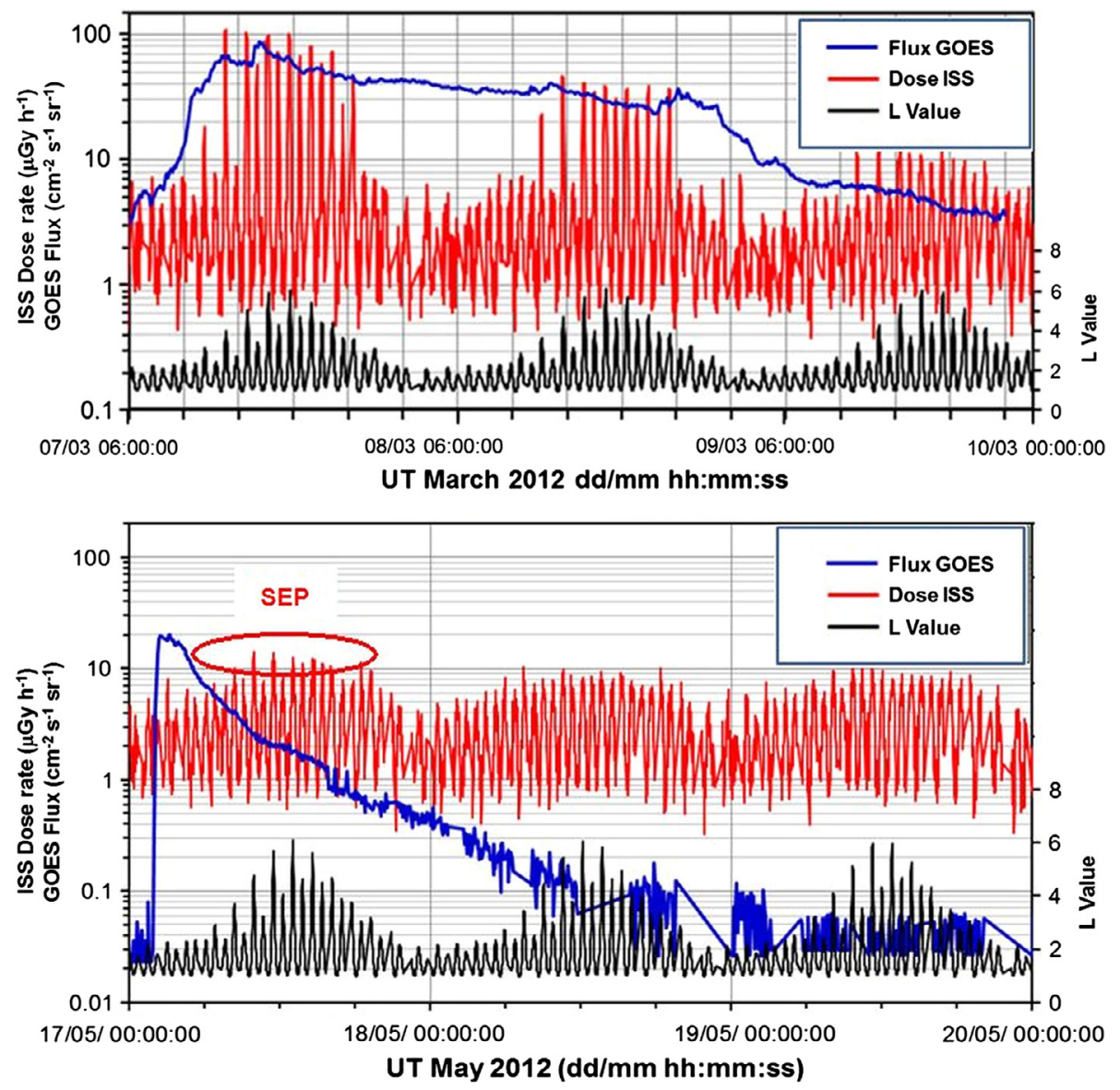

Fig. 7. Proton flux $F$ with energies $\geq 100 \mathrm{MeV}$ measured by GOES-13 (blue curve), the dose rate in D1 detector of Liulin-5 measured outside the SAA (red curve), and the corresponding $L$-values (black curve) versus time. Upper plot (taken from Semkova et al. 2013c) displays data from March 07, 07:00 UT to March 09, 22:00 UT, 2012. Bottom plot - data from May 17, 00:00 UT to May 20, 00:00 UT, 2012.

$\mathrm{Ee}>10 \mathrm{MeV}$, and Ep $>100 \mathrm{MeV}$. Liulin was in active operation on Mir from 1989 to 1994. Liulin has collected data about the radiation environment during a number of SEP events in September-October 1989, March 1991, June 1991, and June 1992 (Benghin et al. 1991; Dachev et al. 1992, 1998; Petrov et al. 1994; Smart et al. 1994; Shurshakov et al. 1999). During the measurements in September-October 1989, the Mir space station orbit was at altitude $380-420 \mathrm{~km}$ and inclination $51.6^{\circ}$. During the SEP event on 29-30 September 1989 (a solar flare of X9.8 importance) when the space station reached high latitudes in the near-polar geomagnetic regions $(L>3.5)$ the dose rate and the flux showed a sharp rise up to $2 \mathrm{mGy} \mathrm{h}^{-1}$ and $150 \mathrm{~cm}^{-2} \mathrm{~s}^{-1}$, respectively. The flux exceeded 150 times and the dose rate exceeded 500-600 times the common values for those regions in the absence of SEPs.

In the upper plot of Figure 8 the flux, absorbed dose rate, and ratio absorbed dose/flux measured by the D1 detector of Liulin-5 on ISS during the SEP event on 07 March 2012 from 17:20:08 UT to 17:46:30 UT are plotted versus $L$ value. In the bottom plot of Figure 8 are plotted the same parameters obtained by the Liulin dosimeter on Mir space station during the SEP event on 30 September 1989 from 00:54:10 UT to 01:18:40 UT. The data in both plots are taken outside the SAA. Comparing the results of Liulin on the Mir space station for the SEP event on 29-30 September 1989 with those of Liulin-5 on the ISS for the SEP event on 07 March 2012 it is evident, that the SEP effect on the Mir radiation environment was much more dramatic than that on the ISS environment. Several facts contribute to that difference: (1) during the SEP event on 29-30 September 1989, when the sharp enhancement in the Liulin data was registered, the GOES proton flux with energies $>100 \mathrm{MeV}$ was $250 \mathrm{~cm}^{-2} \mathrm{~s}^{-1}$, about five times larger than in the 07 March 2012 event at 13:06 (the maximum in Liulin-5 data) when it was $\sim 50 \mathrm{~cm}^{-2} \mathrm{~s}^{-1}$; (2) the two instruments were behind different shielding: the shielding for Liulin on Mir is evaluated to be $6-15 \mathrm{~g} \mathrm{~cm}^{-2}$; that of Liulin-5 on the ISS, when it was in the PIRS module, was $2-20 \mathrm{~g} \mathrm{~cm}^{-2}$ for D1. Our estimations show that the shielding for Liulin-5 while it is in the phantom behind panel 206 in the MIM1 module is greater than in the PIRS module; (3) another cause for the difference could be the different energy spectrum of the SEP events.

The radiation environment on the ISS is observed also by the detectors DB8 of the radiation monitoring system (RMS) since August 2001 (Benghin et al. 2005, 2013). DB8 is a set of four identical units. Each of the units consists of two silicon detectors. The area of each detector is $1 \mathrm{~cm}^{2}$ and the thickness is $300 \mu \mathrm{m}$. One of the detectors inside each DB- 8 unit is protected by a sphere of lead surrounding the detector. The thickness of the lead sphere is $2.5 \mathrm{~mm}\left(3 \mathrm{~g} \mathrm{~cm}^{-2}\right)$. The four DB8 units are located behind different shielding in different points inside the ISS Service module. Thus the RMS provides monitoring of the dose rate dynamics in a few points of the ISS Service module. The shielding of DB- 8 detectors is 
Table 3. Summary of results obtained during some of the largest SEP events from different experiments for radiation measurements with silicon detectors onboard Mir and ISS during 22nd, 23rd and 24th solar cycles. The analytical fits of the total event spectra and peak event spectra for the energy channels of the SEPEM proton reference dataset and reference event list (http://dev.sepem.oma.be/) for these SEP events are shown in Columns 5 and 6.

\begin{tabular}{|c|c|c|c|c|c|}
\hline $\begin{array}{c}\text { (Detector/Space } \\
\text { station-Module/ } \\
\text { Time span }\end{array}$ & Detector shielding & $\begin{array}{c}\text { Time interval } \\
\text { including SEP event } \\
\text { based on SEPEM }\end{array}$ & $\begin{array}{l}\text { Total dose from } \\
\text { SEPs }[\mu \mathrm{Gy}]\end{array}$ & $\begin{array}{l}\text { Total event spectrum } \\
\text { (SEPEM fits) }\end{array}$ & $\begin{array}{l}\text { Peak event spectrum } \\
\text { (SEPEM fits) }\end{array}$ \\
\hline $\begin{array}{l}\text { Liulin/Mir/ } \\
\text { 1989-1994 }\end{array}$ & $6-15 \mathrm{~g} \mathrm{~cm}^{-2}$ & $29.09-10.10 .1989$ & 3100 & $F=5 \mathrm{E}+09 \mathrm{E}^{-2.23}$ & $F=3.13 \mathrm{E}+04 \mathrm{E}^{-2.05}$ \\
\hline $\begin{array}{l}\text { DB8/ISS-SM/ } \\
\text { since } 10.2001\end{array}$ & $\begin{array}{l}6-600 \mathrm{~g} \mathrm{~cm}^{-2} \\
\text { (most shielded) } \\
1-600 \mathrm{~g} \mathrm{~cm}^{-2} \\
\text { (least shielded) }\end{array}$ & $26.10-09.11 .2003$ & $\begin{array}{l}730 \text { (most shielded) } \\
6600 \text { (least shielded) }\end{array}$ & $F=1.46 \mathrm{E}+11 \mathrm{E}^{-2.69}$ & $F=7.66 \mathrm{E}+06 \mathrm{E}^{-3.15}$ \\
\hline $\begin{array}{l}\text { Liulin-5/ISS- } \\
\text { MIM1/since } \\
12.2011\end{array}$ & $>20 \mathrm{~g} \mathrm{~cm}^{-2}$ & 05.03-17.03.2012 & 180 & $F=2.93 \mathrm{E}+10 \mathrm{E}^{-2.74}$ & $F=1.86 \mathrm{E}+06 \mathrm{E}^{-3.12}$ \\
\hline
\end{tabular}

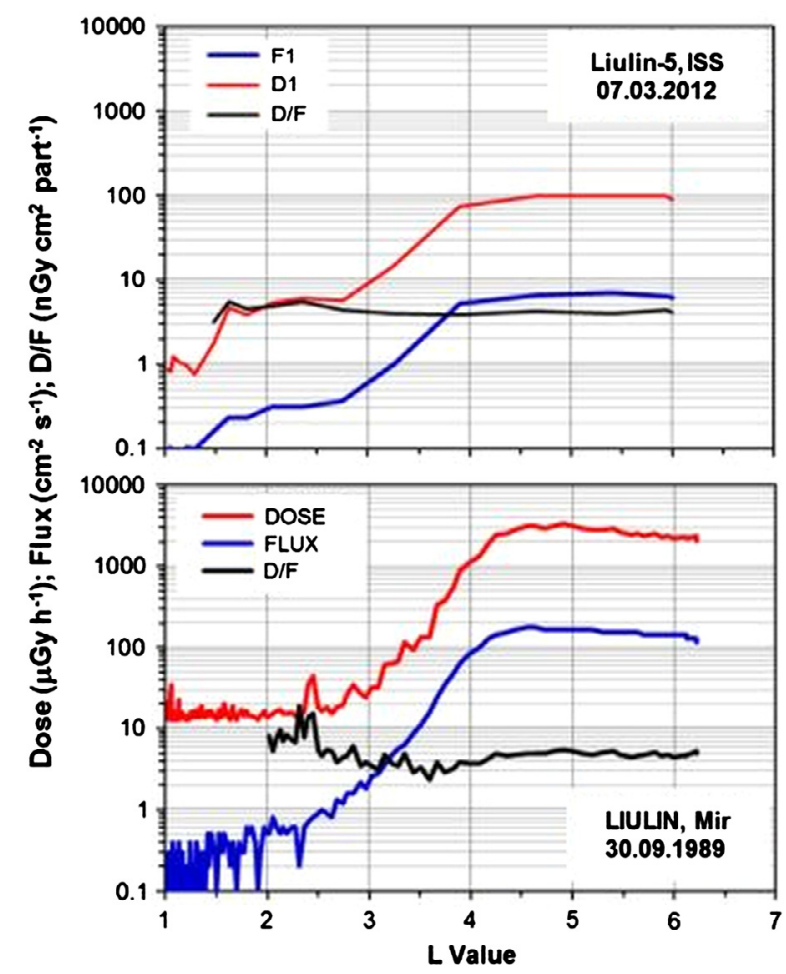

Fig. 8. Flux (blue curves) absorbed dose rate (red curves) and ratio absorbed dose/flux (black curves) versus $L$ value. Upper plot displays the data by the D1 detector of Liulin-5 on the ISS during the SEP event on 07 March 2012 from 17:20:08 UT to 17:46:30 UT. The bottom plot displays the same parameters obtained by the Liulin dosimeter on the Mir space station during the SEP event on 30 September 1989 from 00:54:10 UT to 01:18:40 UT. The data in both plots are taken outside the SAA.

$1-600 \mathrm{~g} \mathrm{~cm}^{-2}$ (least shielded) and $6-600 \mathrm{~g} \mathrm{~cm}^{-2}$ (most shielded). During the maximum of the 23rd solar cycle (2001-2004) four SEP events were monitored (24 September 2001, 04 November 2001, 28 October 2003, and 30 October 2003). The absorbed doses and dose equivalents during those events differ in different points depending on the shielding. The largest values were obtained during the SEP event that started on 28 October 2003, when the minimal absorbed dose and dose equivalents were, respectively, $600 \mu \mathrm{Gy}$ and $1.1 \mathrm{mSv}$ at the most shielded point, maximal values reached $6.6 \mathrm{mGy}$ and $12 \mathrm{mSv}$ at the least shielded point. Model extrapolations made by the authors predict $2.6 \mathrm{mSv}$ dose equivalent to the BFOs in the Service module of ISS during that SEP event. For comparison during the SEP event of 07 March 2012 the minimal absorbed dose measured by DB8 was $550 \mu \mathrm{Gy}$ at the most shielded point and $1.84 \mathrm{mGy}$ at the least shielded shielded point. ${ }^{1}$

The comparison of RMS results from the SEP event on 28 October 2003 with Liulin-5 results on 07 March 2012 is also not very simple. The SEP event on 28 October 2003 had a proton flux with energies $>100 \mathrm{MeV} 100-200 \mathrm{~cm}^{-2} \mathrm{~s}^{-1}$, and is thus 2-4 times more than the SEP event on 07 March 2012. The shielding of the Liulin-5 detectors during the March 2012 event is greater than that of the most shielded DB-8 (according to Fig. 7 in Semkova et al. 2013c). The total dose equivalent of the D1 detector of Liulin-5 (shielding approximately as that of BFO in MIM1) from the SEP event on 07 March 2012 is $0.45 \mathrm{mSv}$ and is thus 5.8 times less than the model extrapolation in Benghin et al. (2005) for the SEP event on 28 October 2003.

The proton fluence spectra for the September 1989, October 2003, and March 2012 SEP events were generated using the ESA's Solar Energetic Particle Environment Modelling (SEPEM) application server (http://dev.sepem.oma.be/). A summary of the results obtained during those SEP events from Liulin on the Mir station and from DB8 and Liulin-5 on the ISS, as well as the analytical fits of the total event spectra and peak event spectra for the energy channels of the SEPEM proton reference dataset and reference event list for those SEP events are shown in Table 3. Both total event and peak event spectra show that $>100 \mathrm{MeV}$ proton flux during the September 1989 and October 2003 SEP events is several times higher than that during the March 2012 SEP event.

\footnotetext{
${ }^{1}$ Benghin V.V., V.M. Petrov, M.I. Panasyuk, O.Yu. Nechaev, I.V. Nikolaev, A.N. Volkov, V.I. Liagushin, and A.E. Lishnevskii, Results of the Radiation Monitoring System Measurements on Service Module of ISS during 2009-2013, 18-th Workshop on Radiation Monitoring for the International Space Station, 3-5 September 2013, Budapest, Hungary, http://wrmiss.org/workshops/eighteenth/ Benghin.pdf.
} 
These results show that the radiation doses inside manned space stations during some of the largest SEP events of previous solar cycles were significantly greater in comparison with the doses during the most significant SEP event of the current cycle (that of 07 March 2012).

\section{Conclusion}

We analyzed the radiation environment in the ISS as deduced from Liulin-5 data for the period 2012-March 2013 around the maximum of the 24th solar cycle. During this period the Liulin-5 instrument was mounted in the MIM1 module of the ISS either outside or inside the spherical tissue-equivalent phantom of the MATROSHKA-R experiment. The dose rates outside the phantom are 210-240 $\mu \mathrm{Gy}$ day $^{-1}$. Near the phantom's center the dose rates are $130-150 \mu \mathrm{Gy}_{\text {day }}{ }^{-1}$. This decreasing in the dose rates inside the phantom is mainly due to its self-shielding against the SAA trapped protons. The SAA dose rates are $120-160 \mu \mathrm{Gy} \mathrm{day}^{-1}$ outside the phantom and 50-70 $\mu \mathrm{Gy} \mathrm{day}^{-1}$ near the center of the phantom. The GCR dose rates are $70-85 \mu \mathrm{Gy}_{\mathrm{day}}{ }^{-1}$. The dose rates from GCRs are practically not affected by the phantom self-shielding. The lowest values of GCR dose rates are observed in July-August 2012, when the detector module was located outside the phantom. This GCR behavior is consistent with the Oulu neutron monitor count rate data for the same period.

The main results regarding measurements performed during the SEP events are as follows:

- During the SEP events on 07-12 March 2012 at $L>3$ the particle flux and dose rates increased in all three detectors of the Liulin-5 charged particle telescope located at 40 , 60 , and $165 \mathrm{~mm}$ depths along the radius of the tissueequivalent spherical phantom. The maximum flux at $40 \mathrm{~mm}$ depth outside the SAA during the SEP events was 7.2 part $\mathrm{cm}^{-2} \mathrm{~s}^{-1}$ and the maximum dose rate was $107.8 \mu \mathrm{Gy} \mathrm{h}^{-1}$ at $L=4$, latitude $=-51.1^{\circ}, \quad$ longitude $=166.8^{\circ}, \quad$ altitude $=422 \mathrm{~km}$. The additional absorbed dose, compared to the common values at $40 \mathrm{~mm}$ depth in the phantom, received from those SEP events was about $180 \mu \mathrm{Gy}$ and the additional dose equivalent was about $448 \mu \mathrm{Sv}$. The additional exposures received from the SEPs at depths corresponding to the shielding of the BFOs in the human body are comparable to the averaged daily absorbed dose and dose equivalent measured at those depths in the spherical phantom in the ISS during quiet periods. The Liulin-5 absorbed dose at $40 \mathrm{~mm}$ depth in the phantom located in the MIM1 module of ISS for those events is about three times less than the dose by the most shielded DB8 detector of the radiation monitoring system located in the ISS Service module.

- On the other hand the SEP event of May 17, 2012 did not cause significant increase of the absorbed dose rate and particle flux inside the phantom. The quality factor and dose equivalent are practically the same as before the event. The reason for that is the low intensity of the SEP event as well as the ISS low $L$ values location when the GOES proton flux with energies greater than $100 \mathrm{MeV}$ was above 5 part $\mathrm{cm}^{-2} \mathrm{~s}^{-1}$.
- During the SEP events in March 07 and May 17, 2012 at $L>3$ the trend of the Liulin-5 dose rates is consistent with the proton flux with energies $\geq 100 \mathrm{MeV}$ measured by the GOES - 13 satellite.

- The other 11 SEP events that occurred in 2012 did not produce significant changes in the radiation conditions inside the ISS according to Liulin-5 data either due to the ISS location during the maximum of SEPs or due to the intensity of the SEP event.

- The largest SEP events during the 22nd and the 23rd solar cycles caused more severe changes in the radiation conditions on the manned Mir space station and the ISS than the most significant SEP event (07 March 2012) of the current 24th cycle. That is mainly because the 07 March 2012 SEP event was several times less intensive than the most intensive SEP events during the previous cycles.

The Liulin-5 experiment continues onboard the ISS in order to obtain more data about the radiation conditions during the current 24th solar cycle that differs from the previous cycles. The ISS is the only current mission and the only place where dosimetric measurements are performed inside tissue-equivalent phantoms - models of human body. The obtained data from Liulin-5 are of importance for the assessment of the radiation doses in the critical organs of the human body and for assessment of the doses in the human body from environmental radiation measurements, provided by a number of radiation detectors on the ISS. The Liulin-5 experiment results will help to improve the models, that simulate biological doses during long-term human space travel and to provide for accurate radiation risk estimates in future interplanetary manned flights.

Acknowledgements. This work is partly supported by Grant No. DID-02/8 from NSF-Bulgaria and by the Agreement between BAS and RAS on fundamental space research. Authors are thankful to RKK Energia and the cosmonauts for conducting the experiments with Liulin-5 and providing data on Liulin-5 location on ISS. Thanks to NIRS, Chiba-Japan for the organization of the calibrations of Liulin-5 instrument at HIMAC. The authors are very thankful to the Referee for editing the manuscript and for the valuable comments and suggestions.

The editor thanks Norma Crosby and two anonymous referees for their assistance in evaluating this paper.

\section{References}

Apathy, I., Yu.A. Akatov, V.V. Arkhangelsky, L. Bodnár, S. Deme, et al. TL dose measurements on board the Russian segment of the ISS by the "Pille" system during Expedition-8, -9 and -10. Acta Astronaut., 60, 322-328, 2007,

DOI: $10.1016 /$ j.actaastro.2006.09.037.

Benghin, V.V., N.G. Bankov, Ts.P. Dachev, M.V. Zill, and Yu.N. Matviichuk, et al. Dynamics of the radiation conditions on the Mir space station orbit during solar proton event of 29 September 1989. Bulletin of the Russian Academy of Sciences: Physics, $\mathbf{5 5}$ (10), 1901, 1991 (in Russian).

Benghin, V.V., V.M. Petrov, S.A. Kireeva, A.V. Markov, A.N. Volkov, et al. Analysis of radiation dose increases caused by solar cosmic ray events observed by the radiation monitoring system on the Russian segment of the international space station. Adv. Space Res., 36 (9), 1749-1752, 2005.

Cliver, E.W., and H.V. Cane. The last word: gradual and impulsive solar energetic particle events. Eos, Trans. AGU, 83, 61, 2002, DOI: $10.1029 / 2002 \mathrm{EO} 000040$. 
Cucinotta, F.A., W. Schimmerling, J.W. Wilson, L.E. Peterson, P.B. Saganti, and J.F. Dicello. Uncertainties in estimates of the risks of late effects from space radiation. Adv. Space Res., 34, 1383-1389, 2004, DOI: 10.1016/j.asr.2003.10.053.

Dachev, Ts.P., Yu.N. Matviichuk, J.V. Semkova, R.T. Koleva, B. Boichev, et al. Space radiation dosimetry with active detections for the scientific program of the second Bulgarian cosmonaut on board the MIR space station. Adv. Space Res., 9 (10), 247-251, 1989, DOI: 10.1016/0273-1177(89)90445-6.

Dachev, Ts.P., Yu.N. Matviichuk, N.G. Bankov, J.V. Semkova, Ya.J. Ivanov, et al. "Mir" Radiation dosimetry results during the solar proton events in September-October 1989. Adv. Space Res., 12 (2-2), 321-324, 1992, DOI: 10.1016/0273-1177(92)90122-E.

Dachev, Ts.P., J.V. Semkova, Yu.N. Matviichuk, B.T. Tomov, R.T Koleva, P.T. Baynov, V.M. Petrov, V.V. Shurshakov, and Yu. Ivanov. Inner magnetosphere variations after Solar Proton Events. Observations on MIR space station in 1989-1994 time period. Adv. Space Res., 22 (4), 521-526, 1998 DOI: 10.1016/S0273-1177(98)01073-4.

Dachev, T.P., J. Semkova, B. Tomov, Yu. Matviichuk, Pl. Dimitrov, et al. Space Shuttle drops down the SAA doses on ISS. Adv. Space Res., 47, 2030-2038, 2011, DOI: 10.1016/j.asr.2011.01.034.

Dachev, Ts.P., B.T. Tomov, Yu.N. Matviichuk, Pl.G. Dimitrov, N.G. Bankov, G. Reitz, G. Horneck, D.-P. Häder, M. Lebertd, and M. Schusterd. Relativistic electron fluxes and dose rate variations during April-May 2010 geomagnetic disturbances in the R3DR data on ISS. Adv. Space Res., 50, 282-292, 2012,

DOI: 10.1016/j.asr.2012.03.028

Davis, A.J., R.A. Mewaldt, C.M.S. Cohen, A.C. Cummings, J.S. George, et al. Solar minimum spectra of galactic cosmic rays and their implications for models of the near-earth radiation environment. J. Geophys. Res., 106, 29979-29987, 2001, DOI: 10.1029/2000JA000325.

De Angelis, G., B.M. Anderson, W. Atwell, J.E. Nealy, G.D. Qualls, and J.W. Wilson. Astronaut EVA exposure estimates from CAD model spacesuit geometry. J. Radiat. Res., 45, 1-9, 2004, DOI: 10.1269 /jrr.45.1.

Dettmann, J., G. Reitz, and G. Gianfiglio. MATROSHKA - The first ESA external payload on the international space station. Acta Astronaut., 60 (1), 17-23, 2007,

DOI: 10.1016/j.actaastro.2006.04.018.

Golightly, M.J., A.C. Hardy, W. Atwell, and K. Hardy. Description, analysis and impact of major solar activity during recent U.S. shuttle missions. Adv. Space Res., 12 (2-3), 335-338, 1992, DOI: 10.1016/0273-1177(92)90125-H.

ICRP. 1990 Recommendations of the International Commission on Radiological Protection. ICRP Publication 60. Ann. ICRP, 21 (1-3), 4-11, 1991.

Kartsev, I.S., Yu.A. Akatov, V.G. Eremenko, V.I. Petrov, V.M. Petrov, et al. Spherical phantom for studying radiation conditions in outer space. Design-structural special features. Nuclear Measurement \& Information Technologies, 16, 36-45, 2005.

Lobakov, A.P., V.I. Liagushin, M.I. Panasiuk, P.I. Shavrin, V.S. Makhmutov, V.M. Petrov, V.A. Shurshakov, Ts.P. Dachev, and I.V Semkova. Increase of solar cosmic rays on the "MIR" Space station in orbit during September-October 1989. Nuclear Tracks and Radiation Measurements, 20 (1), 59-64, 1992, DOI: 10.1016/1359-0189(92)90086-B.

Mewaldt, R.A., A.J. Davis, K.A. Lave, R.A. Leske, E.C. Stone, et al. Record-setting cosmic-ray intensities in 2009 and 2010. Astrophys. J. Lett., 723, L1-L6, 2010, DOI: $10.1088 / 2041-8205 / 723 / 1 / \mathrm{L} 1$

Nymmik, R.A. Improved environment radiation models. Adv. Space Res., 40, 313-320, 2007, DOI: 10.1016/j.asr.2006.12.028.

O'Neill, P.M. Badhwar-O'Neill galactic cosmic ray model update based on advanced composition explorer (ACE) energy spectra from 1997 to present. Adv. Space Res., 37 (9), 1727-1733, 2006, DOI: $10.1016 / j$.asr.2005.02.001.

Petrov, V.M., V.S. Machmutov, N.A. Panova, V.A. Shurshakov, Ts.P. Dachev, J.V. Semkova, and Yu.P. Matvijchuk. Peculiarities of the solar proton events of 19 October 1989 and 23 March 1991 according to the measurements on board the MIR space station. Adv. Space Res., 14 (10), 645-650, 1994, DOI: 10.1016/0273-1177(94)90520-7.

Reitz, G., and T. Berger. The MATROSHKA facility - dose determination during an EVA. Radiat. Prot. Dosim., 120, 442-445, 2007.

Reitz, G., T. Berger, P. Bilski, R. Facius, M. Hajek, et al. Astronaut's organ doses inferred from measurements in a human phantom outside the international space station. Radiat. Res., 171 (2), 225-235, 2009, DOI: 10.1667/RR1559.1.

Sawyer, D.M., and J.I. Vette. AP-8 trapped proton environments for solar maximum and solar minimum. NSSDC/WDC-A-R\& S76-06, 1976, http://ccmc.gsfc.nasa.gov/modelweb/magnetos/AP-8-minmax-76-6.pdf.

Semkova, J., R. Koleva, S. Maltchev, N. Kanchev, V. Benghin, et al. Radiation measurements inside a human phantom aboard the international space station using Liulin-5 charged particle telescope. Adv. Space Res., 45 (7), 858-865, 2010, DOI: 10.1016/j.asr.2009.08.027.

Semkova, J., and R. Koleva. Overview on the radiation quantities observed by Liulin-5 instrument in a Human Phantom on international space station during the minimum of $23 \mathrm{rd}$ solar cycle. Compt. Rend. Acad. Bulg. Sci., 63 (10), 1533-1542, 2010.

Semkova, J., R. Koleva, St. Maltchev, N. Bankov, V. Benghin, I. Chernykh, V. Shurshakov, V. Petrov, S. Drobyshev, and I. Nikolaev. Depth dose measurements with the Liulin-5 experiment inside the spherical phantom of the Matroshka-R project onboard the international space station. Adv. Space Res., 49, 471-478, 2012, DOI: 10.1016/j.asr.2011.10.005.

Semkova, J., R. Koleva, S. Maltchev, N. Bankov, V. Benghin, I. Chernykh, V. Shurshakov, and V. Petrov. Radiation characteristics in the spherical tissue-equivalent phantom on the ISS during solar activity minimum according the data from Liulin-5 experiment. J. Atmos. Sol. Terr. Phys., 99, 157-163, 2013a, DOI: $10.1016 /$ j.jastp.2012.07.006.

Semkova, J., R. Koleva, N. Bankov, St. Malchev, and V.M. Petrov. Study of radiation conditions onboard the International space station by means of the Liulin-5 dosimeter. Cosmic Res., 51 (2), 124-132, 2013b, DOI: 10.1134/S0010952512060068.

Semkova, J., T. Dachev, R. Koleva, S. Maltchev, N. Bankov, V. Benghin, V. Shurshakov, V. Petrov, and S. Drobyshev. Radiation environment on the international space station during the solar particle events in March 2012. Astrol. Outreach, 1, 102, 2013c, DOI: $10.4172 / 2332-2519.1000102$.

Shurshakov, V.A., V.M. Petrov, N.A. Panova, Yu.V. Ivanov, V.S Makhmutov, Ts. Dachev, and J. Semkova. Experimental investigations of quasistable radiation belts formed after solar proton events in September-October 1989 and March 1991 based on measurements made by Liulin dosimeter-radiometer on board the Mir space station. Adv. Space Res., 18 (12), 251-256, 1996, DOI: $10.1016 / 0273-1177(96) 00020-8$.

Shurshakov, V.A., V.M. Petrov, Yu.V. Ivanov, V.A. Bondarenko, V.V. Tzetlin, V.S. Makhmutov, Ts.P. Dachevc, and J.V. Semkova. Solar particle events observed on MIR station. Radiat. Meas., 30 (3), 317-325, 1999, DOI: 10.1016/S1350-4487(99)00058-X.

Shurshakov, V.A., Yu.A. Akatov, I.S. Kartsev, V.M. Petrov, R.V. Tolochek, et al. Study of dose distribution in a human body in Space Station compartments with the spherical tissue-equivalent phantom, Proceedings of the International Conference "Fundamental Space Research", Sunny Beach, Bulgaria, September 21-28, 234-238, ISBN: 978-954-322-316-9, 2008.

Simpson, J.A. Introduction to the galactic cosmic radiation. In: M.M., Shapiro, Editor, Composition and origin of cosmic rays, NATO ASI Series C: Mathematical and Physical Sciences, 107, Reidel, Dordrecht, 1-24, ISBN-10: 9027716099 / ISBN-13: 978-9027716095, 1983.

Smart, D.F., M.A. Shea, Ts.P. Dachev, N.G. Bankov, V.M. Petrov, and V.V. Bengin. The dose rate observed on 19-21 October 1989 
and its modulation by geophysical effects. Adv. Space Res., 14 (10), 651-654, 1994, DOI: 10.1016/0273-1177(94)90521-5.

Vette, J.I. The NASA/National Space Science Data Center Trapped Radiation Environmental Model Program (1964-1991). NSSDC/ WDC-A-R\&91-29, 1991, http://ntrs.nasa.gov/archive/nasa/ casi.ntrs.nasa.gov/19930001815.pdf.
Wilson, J.W., F.F. Badavi, M.Y. Kim, M.S. Clowdsley, J.H. Heinbockel, F.A. Cucinotta, G.D. Badhwar, W. Atwell, and S.L. Huston. Natural and induced environment in low Earth orbit. NASA TM-2002-211668, 2002, http://ntrs.nasa.gov/archive/nasa/ casi.ntrs.nasa.gov/20020051124.pdf.

Cite this article as: Semkova, J., T. Dachev, R. Koleva, N. Bankov, S. Maltchev, et al. Observation of radiation environment in the International Space Station in 2012-March 2013 by Liulin-5 particle telescope. J. Space Weather Space Clim., 4, A32, 2014, DOI: $10.1051 / \mathrm{swsc} / 2014029$. 